\title{
Analisis Pembebanan Struktur Bangunan Atas Gedung Kantor Kelurahan Kampung Baru Raya Bandar Lampung
}

\author{
Suirna Juarnisa Syahland ${ }^{(1)^{*}}$, Martina Anggi Silova ${ }^{(2)}$ \\ ${ }^{(1)}$ Universitas Sang Bumi Ruwa Jurai, ${ }^{(2)}$ Universitas Sang Bumi Ruwa Jurai \\ email korespondensi: suirnajuarnisasyahland@gmail.com ${ }^{{ }^{*}}$
}

\begin{abstract}
Abstrak.
Tujuan dari penelitian ini adalah untuk menganalisis evaluasi gaya ultimate yang bekerja pada kolom, balok, dan plat lantai kemudian mendesain keperluan tulangannya dengan dimensi kolom, balok dan plat sesuai dengan ukuran yang ada pada gambar kerja, dan membandingkan kapasitas daya dukung komponen tersebut apakah sudah sesuai dengan kapasitas yang direncanakan atau belum. Metode yang digunakan yaitu metode SRPMK adalah suatu rangka ruang dimana komponen-komponen struktur dan join-joinya dapat menahan gaya - gaya yang bekerja melalui aksi lentur, geser dan aksial untuk daerah resiko gempa tinggi. Dan menghitung dibantu dengan aplikasi SAP2000 versi 14, agar perhitungan lebih mudah dan cepat. Hasil yang yaitu untuk penulangan plat lantai dipakai tulangan untuk arah x $\phi 10$ -100 dan untuk arah y $\phi 10-100$. Perencanaan balok menggunakan mutu baja fy $=400 \mathrm{Mpa}$ dan mutu beton fc' $=$ 24.90 Mpa dengan ukuran balok untuk Balok B1 $25 \mathrm{~cm}$ x $40 \mathrm{~cm}$, Balok B3 $20 \mathrm{~cm}$ x 40cm, Balok B4 $15 \mathrm{~cm}$ x $30 \mathrm{~cm}$, dan Balok B5 $20 \mathrm{~cm}$ x $40 \mathrm{~cm}$. Sedangkan untuk perencanaan kolom memakai mutu baja fy $=400 \mathrm{Mpa}$ dan mutu beton fc' $=24.90$ Mpa dengan ukuran untuk lantai 1 Kolom K1 35cm x 35cm, Kolom K3 25cm x 25cm dan untuk lantai $235 \mathrm{~cm}$ x $35 \mathrm{~cm}$. Setelah melakukan penganalisaan struktur, adanya perbedaan kapasitas penulangan dikarenakan adanya perbedaan asumsi pembebanan pada proses perencanaan, adanya penulangan yang terpasang kurang dari persyaratan dari hasil analisis yang ada, sehingga perlu dilakukan perkuatan struktur agar kolom tersebut dapat bertahan, dan untuk tulangan yang terpasang melebihi perhitungan analisis maka yang terpasang sudah aman berdasarkan perencanaan menggunakan pembebanan yang terbaru.
\end{abstract}

Kata Kunci: Kolom, Balok, Plat Lantai, Analisis Pembebanan, Evaluasi Kapasitas Penulangan

\begin{abstract}
.
The purpose of this study was to analyze the evaluation of the ultimate force acting on the columns, beams, and floor slabs then design the reinforcement requirements with the dimensions of the columns, beams and plates according to the sizes on the working drawings, and compare the carrying capacity of these components whether they are appropriate. with the planned capacity or not. The method used is the SRPMK method, which is a space frame where the structural components and their joints can withstand the forces acting through bending, shear and axial action for high earthquake risk areas. And counting is assisted with the SAP2000 version 14 application, so that calculations are easier and faster. The result is that for floor plate reinforcement, reinforcement is used for the $x$ direction $10-$ 100 and for the $y$ direction $10-100$. The design of the beams uses steel quality fy $=400 \mathrm{Mpa}$ and concrete quality $f_{c^{\prime}}=24.90 \mathrm{Mpa}$ with beam sizes for B1 beams $25 \mathrm{~cm} \times 40 \mathrm{~cm}, B 3$ beams $20 \mathrm{~cm} \times 40 \mathrm{~cm}, \mathrm{~B} 4$ beams $15 \mathrm{~cm} \times 30 \mathrm{~cm}$, and $B 5$ beams $20 \mathrm{~cm} \times 40 \mathrm{~cm}$. As for the column planning, the steel quality fy $=400 \mathrm{MPa}$ and the concrete quality $\mathrm{fc}^{\prime}=$ $24.90 \mathrm{MPa}$ with dimensions for the 1 st floor of $35 \mathrm{~cm} \times 35 \mathrm{~cm} \mathrm{K1}$ column, $25 \mathrm{~cm} \times 25 \mathrm{~cm} \mathrm{K3}$ column and $35 \mathrm{~cm} \times 35 \mathrm{~cm}$ for the 2 nd floor. After analyzing the structure, there is a difference in reinforcement capacity due to differences in loading assumptions in the planning process, the installed reinforcement is less than the requirements from the existing analysis results, so it is necessary to strengthen the structure so that the column can survive, and for the installed reinforcement exceeds the analysis calculation. then the installed is safe based on the plan using the latest loading.
\end{abstract}

Keywords: Columns, Beams, Slabs, Loading Analysis, Evaluation of Reinforcement Capacity 


\section{PENDAHULUAN}

Di dalam perencanaan suatu gedung, sesuai dengan fungsinya masing-masing gedung pelayanan masyarakat seperti kantor kelurahan, harus diperhatikan dan direncanakan dengan memperhitungkan segala aspek kenyamanan, kekuatan, dan dari aspek ekonomisnya. Harus memperhitungkan keamanan dan ketelitian yang tinggi sehingga mendapatkan kenyamanan yang diinginkan. Beberapa faktor seperti beban mati, beban hidup dan beban gempa yang dapat mempengaruhi kekuatan dalam suatu konstruksi gedung. Maka perlu dipikirkan dengan cermat bahwa pembangunan sebuah gedung bertingkat dapat meningkatkan resiko terjadinya kekuatan gempa yang ditimbulkan.

Lampung adalah provinsi dengan tingkat kerawanan yang cukup tinggi, kondisi ini memberikan dampak yang cukup besar dalam perencanaan sebuah gedung di wilayah tersebut. Oleh karena itu membutuhkan suatu solusi agar memperkecil resiko yang terjadi akibat gempa, yaitu dalam memperhitungkan segala perhitungan struktur yang ada sangat dibutuhkan para sarjanawan teknik sipil dengan ketelitian yang sangat matang. Sehingga perlunya untuk memahami dan melatih diri dalam merencanakan struktur gedung tahan gempa.

Beberapa komponen struktur gedung terdiri dari pondasi, sloof, kolom, balok, plat lantai, dan plat atap. Masing-masing harus dihitung untuk mengetahui dimensi dan pembebanannya sehingga dapat diketahui kuat atau tidak kuat struktur tersebut. Kota Bandar Lampung merupakan wilayah Zona C $(0,60$ $0,90 \mathrm{~g}$ ) menurut peta wilayah gempa Indonesia SNI 17262012.

Dari uraian di atas, penelitian ini bertujuan dari penelitian ini, adalah untuk menganalisis struktur gedung agar tercapai perencanaan yang memenuhi ketentuan yang disyaratkan, serta mendapatkan hasil pekerjaan struktur yang aman dan ekonomis, dan untuk menghitung beban-beban yang terjadi, peneliti menggunakan software SAP 2000.

\section{METODE PELAKSANAAN}

Teknik pengumpulan data untuk setiap penelitian diperlukan untuk mempermudah dalam pengambilan data maupun pengolahan data. Dalam penelitian ini data - data diperoleh dari data perencanaan dari gedung berupa data - data kolom, balok dan plat lantai dan lain lain yang di dapat dari data proyek di lapangan, data tersebut dpat dilihat pada Tabel 1 dan Tabel 2.

Tabel 1. Kolom

\begin{tabular}{lccccccc}
\hline No & Nama & Jenis & Tulangan & Tulangan & Ukuran & Mutu & Tebal \\
& Kolom & besi & pokok & sengkang & $(\mathbf{c m})$ & $(\mathbf{K})$ & selimut \\
& & & $(\mathbf{D})$ & $($ Ø) & & & beton \\
\hline 1 & Tipe K-1 & Ulir & $15 \mathrm{~mm}$ & $8 \mathrm{~mm}$ & $35 \times 35$ & 300 & $2.5 \mathrm{~cm}$ \\
\hline 2 & Tipe K-2 & Ulir & $15 \mathrm{~mm}$ & $8 \mathrm{~mm}$ & $35 \times 35$ & 300 & $2.5 \mathrm{~cm}$ \\
\hline 3 & Tipe K-3 & Ulir & $13 \mathrm{~mm}$ & $8 \mathrm{~mm}$ & $25 \times 25$ & 300 & $2.5 \mathrm{~cm}$ \\
\hline 5 & Tipe KP & Ulir & $10 \mathrm{~mm}$ & $6 \mathrm{~mm}$ & $11 \times 11$ & 250 & $1.5 \mathrm{~cm}$ \\
\hline
\end{tabular}

Tabel 2. Kolom

\begin{tabular}{cccccccc}
\hline No & $\begin{array}{c}\text { Nama } \\
\text { Bal0k }\end{array}$ & $\begin{array}{c}\text { Jenis } \\
\text { besi }\end{array}$ & $\begin{array}{c}\text { Tulangan } \\
\text { pokok (D) }\end{array}$ & $\begin{array}{c}\text { Tulangan } \\
\text { sengkang }(\emptyset)\end{array}$ & $\begin{array}{c}\text { Ukuran } \\
(\mathbf{c m})\end{array}$ & $\begin{array}{c}\text { Mutu } \\
(\mathbf{K})\end{array}$ & $\begin{array}{c}\text { Tebal selimut } \\
\text { beton }\end{array}$ \\
\hline 1 & B-1 & Ulir & $16 \mathrm{~mm}$ & $8 \mathrm{~mm}$ & $25 \times 45$ & 300 & $2 \mathrm{~cm}$ \\
\hline 2 & B-2 & Ulir & $16 \mathrm{~mm}$ & $8 \mathrm{~mm}$ & $25 \times 45$ & 300 & $2 \mathrm{~cm}$ \\
\hline 3 & B-3 & Ulir & $16 \mathrm{~mm}$ & $8 \mathrm{~mm}$ & $25 \times 40$ & 300 & $2 \mathrm{~cm}$ \\
\hline 4 & B-4 & Ulir & $16 \mathrm{~mm}$ & $8 \mathrm{~mm}$ & $25 \times 40$ & 300 & $2 \mathrm{~cm}$ \\
\hline 5 & B-5 & Ulir & $13 \mathrm{~mm}$ & $8 \mathrm{~mm}$ & $15 \times 30$ & 300 & $2 \mathrm{~cm}$ \\
\hline 6 & Plat & Ulir & $\begin{array}{c}\text { Tulangan } \\
\text { atas } 10 \mathrm{~mm}\end{array}$ & $\begin{array}{c}\text { Tulangan bawah } \\
10 \mathrm{~mm}\end{array}$ & $\begin{array}{c}\text { Tebal } \\
12 \mathrm{~cm}\end{array}$ & 300 & $3 \mathrm{~cm}$ \\
\hline
\end{tabular}

Tahapan dalam penelitian ini yaitu pengujian lapangan, analisis struktur dan analisis perkuatan. Adapun tahapan kegiatan yang dilakukan adalah sebagai berikut :

1. Pengamatan visual langsung di lokasi bangunan untuk melakukan pemeriksaaan kerusakaan seperti retak-retak, keropos, mengelupas ataupun gompalan pada elemen struktur bangunan.

2. Pengumpulan data skunder berupa gambar kerja sebagai pembanding terhadap kondisi dilapangan untuk mendapatkan dimensi struktur beton bertulang yang 
terpasang di lapangan, termasuk dimensi tulangannya.

3. Pengukuran geometri struktur bangunan dengan menggunakan alat Meteran. Kondisi ini dilakukan untuk memastikan apabila gambar kerja kurang lengkap atau tidak jelas.

4. Setelah data primer dn skunder didapatkan, kemudian dilakukan analisis struktur menggunakan program SAP 2000 Ver.14 dalam rangka evaluasi kelayakan struktur yang didasarkan pada laporan hasil penelitian kondisi eksisting yang ada dengan menghitung kapasitas struktur pada bangunan eksisting.

5. Jika didapatkan hasil evaluasi bahwa struktur eksiting masih aman, akan dilakukan penambahan struktur lantai, kemudian dianalisis kembali mengunakan program SAP 2000.

6. Memberikan kesimpulan dan rekomendasi terhadap penelitian yang dilakukan.

\section{HASIL DAN PEMBAHASAN}

Analisis perhitungan berpedoman pada teori yang telah didapat di perkuliahan, dan mengacu pada SNI 2847-2013 tentang Persyaratan beton struktural untuk bangunan gedung, SNI 1728-2012 tentang Tata cara perencanaan ketahanan gempa untuk struktur bangunan gedung dan non gedung, SNI 17272013 tentang Beban minimum untuk perancangan bangunan gedung dan struktur lain, serta dibantu oleh aplikasi SAP2000 versi 14 dan Microsoft Excel dalam menentukan besarnya gaya dalam dan jumlah tulangan perlu, kemudian membandingkannya dengan kolom, balok, plat eksisting yang telah terbangun. Jika kapasitas kolom tidak kuat, maka akan diberikan rekomendasi penanganan agar bangunan mampu bertahan lama.

\section{Analisis Struktur Balok dan Kolom}

\section{a. Pembebanan}

Perhitungan gaya dilakukan dengan bantuan software SAP 2000 dengan memasukkan beban yang bekerja pada struktur yakni beban mati dan berat sendiri.

\section{1) Beban Mati}

Beban mati didefinisikan sebagai beban yang ditimbulkan oleh elemenelemen struktur bangunan; balok, kolom, dan pelat lantai dihitung secara otomatis melalui bantuan program SAP 2000. Beban ini akan dihitung otomatis oleh program SAP 2000. Beban mati tambahan didefinisikan sebagai beban mati yang diakibatkan oleh berat dari elemen-elemen tambahan atau finishing yang bersifat permanen. Rician beban mati tambahan pada proyek pembangunan Kantor Kelurahan Kampung Baru Raya diantaranya:

\section{a) Beban Dinding}

Beban dinding dimasukkan sebagai beban merata pada setiap balok yang menopang dinding, untuk dinding yang tidak berada tepat di atas balok akan dilakukan transfer pembebanan untuk menjadi beban terpusat pada balok. Besarnya beban dinding dapat dihitung dengan rumus: $Q_{\text {dinding }}=$

$h_{\text {dinding }} \times b_{\text {dinding }} \times$ BJ Batu Bata.

\section{b) Beban Pelat}

Beban pelat lantai mempunyai rician sebagai berikut: 
Tabel 3. Beban mati pelat lantai (ASCE 7-

\begin{tabular}{lcrr}
\multicolumn{4}{c}{$10)$} \\
\hline $\begin{array}{c}\text { Beban Mati } \\
(\mathrm{qD})\end{array}$ & Tebal $(\mathrm{m})$ & $\begin{array}{c}\text { Berat Jenis } \\
\left(\mathrm{kN} / \mathrm{m}^{3}\right)\end{array}$ & $\begin{array}{c}\text { Berat } \\
\left(\mathrm{kN} / \mathrm{m}^{2}\right)\end{array}$ \\
\hline Berat Spesi & 0,03 & 21 & 0,63 \\
\hline Berat Keramik & & 0,47 \\
\hline $\begin{array}{l}\text { Berat Plafond }+ \\
\text { Penggantung }\end{array}$ & 0,15 \\
\hline $\begin{array}{l}\text { Berat } \\
\text { Mekanikal } \\
\text { Elektrikal }\end{array}$ & 0,190 \\
\hline \multicolumn{3}{c}{ Total (qD) } \\
\hline
\end{tabular}

\section{c) Beban Kolom Praktis}

Beban kolom praktis dimasukkan sebagai beban terpusat pada balok. Besarnya beban kolom praktis dapat dihitung dengan rumus:

$$
\begin{aligned}
Q_{\text {kolom praktis }}= & h_{\text {kolom praktis }} \\
& \times b_{\text {kolom praktis }} \\
& \times H_{\text {bangunan }} \times \mathrm{Y}_{\text {beton }}
\end{aligned}
$$

Beban Mati diinput pada balok sebagai beban merata dan beban terpusat (beban dinding dan beban kolom praktis) serta pada pelat diinput sebagai beban area (beban pelat).

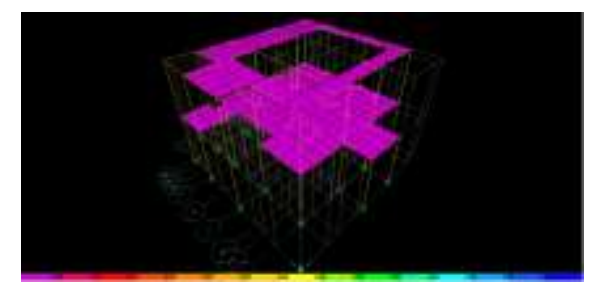

Gambar 1. Input Pembebanan Plat akibat Beban Mati

\section{2) Beban Hidup}

Untuk beban hidup berdasarkan SNI 1727-2013 pada bangunan perkantoran dibagi berdasarkan jenis ruangan dengan rician sebagai berikut:

$\begin{array}{ll}\text { Beban Hidup Atap } & =0,96 \mathrm{kN} / \mathrm{m} 2 \\ \text { Beban Hidup Pelat } & =2.40 \mathrm{kN} / \mathrm{m} 2\end{array}$

Beban hidup diinput ke software SAP2000 v.14 berupa beban area pada pelat. Gambar input pembebanan beban hidup pada pelat lantai 1 , pelat lantai 2 serta pelat atap dapat dilihat pada Gambar 2 dan Gambar 3.

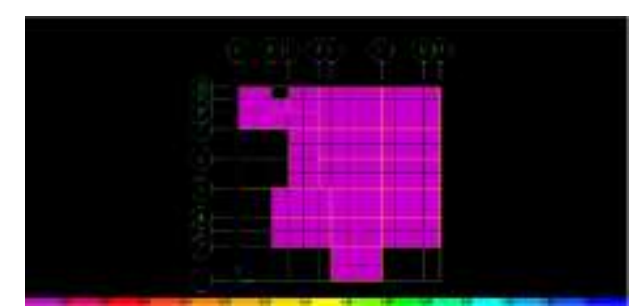

Gambar 2. Input Pembebanan Beban Hidup Pelat Lantai 1

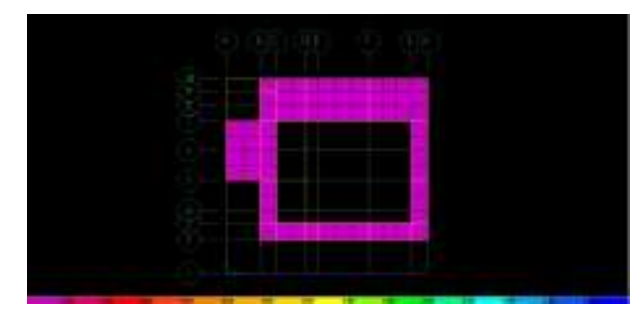

Gambar 3. Input Pembebanan Beban Hidup Pelat Lantai 2

\section{b. Kombinasi Beban}

Dalam SNI 1727-2013 Beban minimum untuk perancangan bangunan gedung dan struktur lain pasal 2.3.2 Kombinasi dasar pembebanan adalah sebagai berikut :

COMB $1=1,4 \mathrm{D}$

COMB $2=1,2 \mathrm{D}+1,6 \mathrm{~L}+0,5 \mathrm{Lr}$

COMB $3=1,2 \mathrm{D}+1,6 \mathrm{Lr}+1,0 \mathrm{~L}$

COMB $4=1,2 \mathrm{D}+1,6 \mathrm{Lr}+0,5 \mathrm{Wx}+0,3 \mathrm{Wy}$

COMB $5=1,2 \mathrm{D}+1,6 \mathrm{Lr}+0.3 \mathrm{Wx}+0,5 \mathrm{Wy}$

COMB $6=1,2 \mathrm{D}+1,0 \mathrm{Wx}+0,3 \mathrm{Wy}+1,0 \mathrm{~L}+$

$0,5 \mathrm{Lr}$

COMB $7=1,2 \mathrm{D}+0,3 \mathrm{Wx}+1,0 \mathrm{Wy}+1,0 \mathrm{~L}+$ $0,5 \mathrm{Lr}$

COMB $8=1,2 \mathrm{D}+1,0 \mathrm{Ex}+0,3 \mathrm{Ey}+1 \mathrm{~L}$

$\mathrm{COMB} 9=1,2 \mathrm{D}+0,3 \mathrm{Ex}+1,0 \mathrm{Ey}+1 \mathrm{~L}$

COMB $10=0,9 \mathrm{D}+1,0 \mathrm{Wx}+0,3 \mathrm{Wy}$

COMB $11=0,9 \mathrm{D}+0,3 \mathrm{Wx}+1,0 \mathrm{Wy}$

COMB $12=0,9 \mathrm{D}+1,0 \mathrm{Ex}+0,3 \mathrm{Ey}$

COMB $13=0,9 \mathrm{D}+0,3 \mathrm{Ex}+1,0 \mathrm{Ey}$

\section{c. Kombinasi Beban Analisis Struktur Bangunan Gedung menggunakan Software program SAP2000 versi 14}

1) Membuat grid untuk memodelkan struktur

a) Klik menu File lalu klik New Model atau klik icon New Model. 
b) Klik drop-down pada layar yang tampak untuk memilih satuan $K N$, $m, \quad C$ sebagai satuan yang digunakan.

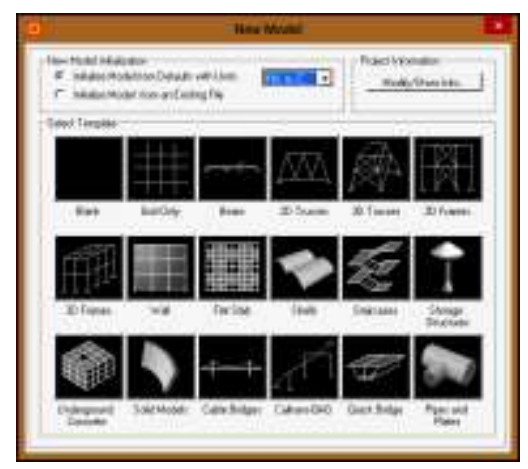

Gambar 4. Layar yang ditampilkan setelah klik icon New Model

c) Kemudian pilih Grid Only sehingga akan ditampilkan kotak Quick Grid Lines seperti pada Gambar 5.

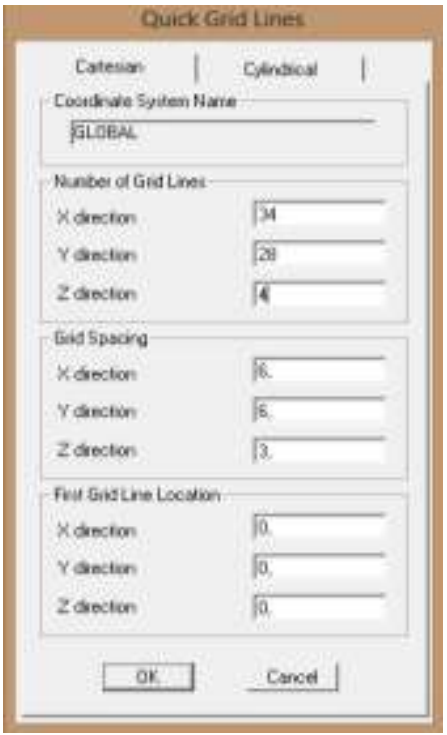

Gambar 5. Kotak Quick Grid Lines

d) Dalam kotak Quick Grid Lines klik tab Cartesian. Pada kotak Number of Grid Lines berfungsi untuk menentukan jumlah titik yang digunakan dalam pemodelan struktur. Karena model yang digunakan adalah struktur gedung 3 dimensi maka dalam kotak Number of Grid Lines untuk semua sumbu (sumbu $\mathrm{X}$, sumbu $\mathrm{Y}$, dan sumbu Z) diisi sesuai dengan data tata letak koordinat gedung. Lalu pada kotak Grid Spacing berfungsi untuk menentukan jarak antar titik pada setiap sumbu. Karena jarak yang digunakan berbedabeda maka Grid Spacing diatur kemudian. Setelah Number of Grid Lines diisi maka selanjutnya klik OK. Tampilan Grid sebelum spasi diatur dapat dilihat pada Gambar 6 dan Gambar 7.

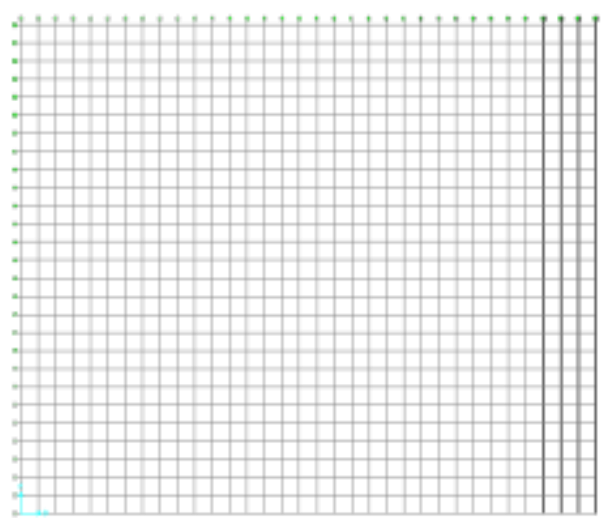

Gambar 6. Tampak atas Grid setelah spasi diatur

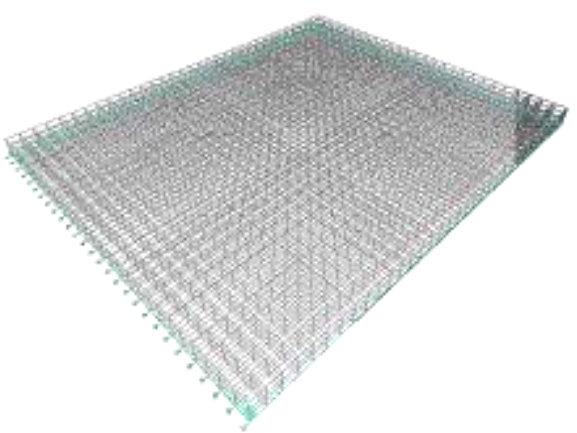

Gambar 7. Tampak atas Grid sebelum spasi diatur

e) Untuk mengatur spasi antar grid dapat dilakukan dengan cara klik kanan pada mouse di layar gambar lalu klik Edit Grid Data. 
Setelah itu akan ditampilkan kotak Coordinate/Grid Systems

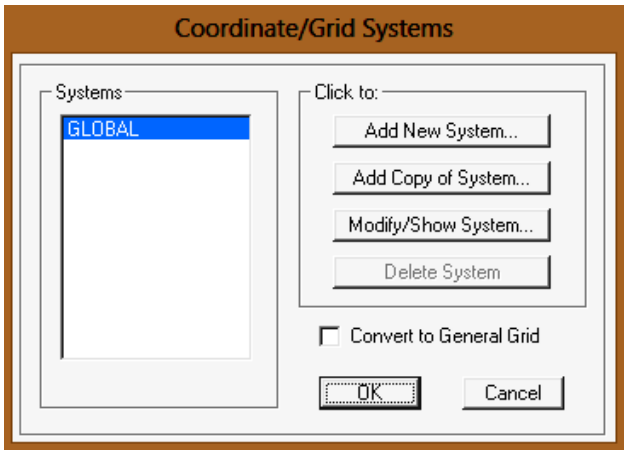

Gambar 8. kotak Coordinate/Grid Systems

Selanjutnya dari kotak Coordinate/Grid Systems klik Modify/Show System pada tab Clik to setelahnya akan ditampilkan kotak Define Grid System Data. Dalam mengatur spasi antar grid dapat dilakukan dengan dua cara, yaitu dengan menggunakan sistem koordinat (Ordinates) serta sistem jarak (Spacing) yang dapat ditemukan pada tab Display Grids as. Tampilan pengaturan spasi antar grid.

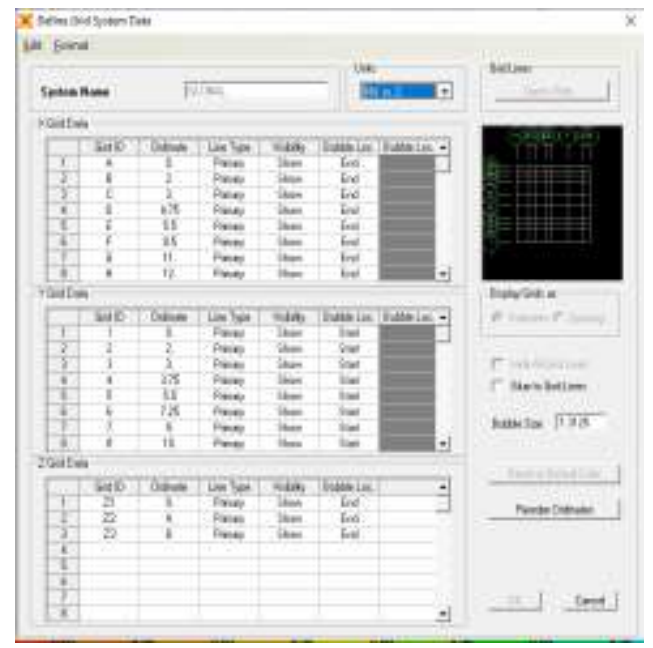

Gambar 9. Pengaturan spasi antar grid dalam SAP2000 versi 14

Pengaturan spasi antar grid dilakukan dengan menyesuaikan koordinat tata letak struktur gedung. Dengan menggunakan sistem jarak
(Spacing) maka nilai jarak antar grid harus berdasarkan jarak titik ke titik dalam sumbu X, sumbu Y, dan sumbu $\mathrm{Z}$.

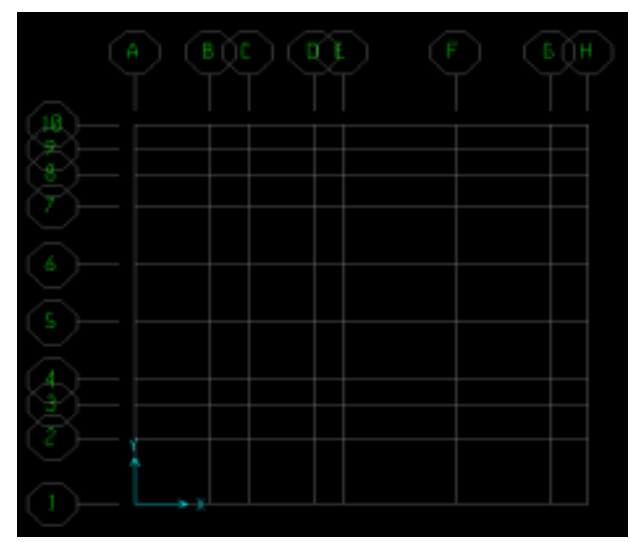

Gambar 10. Tampak atas Grid setelah spasi diatur

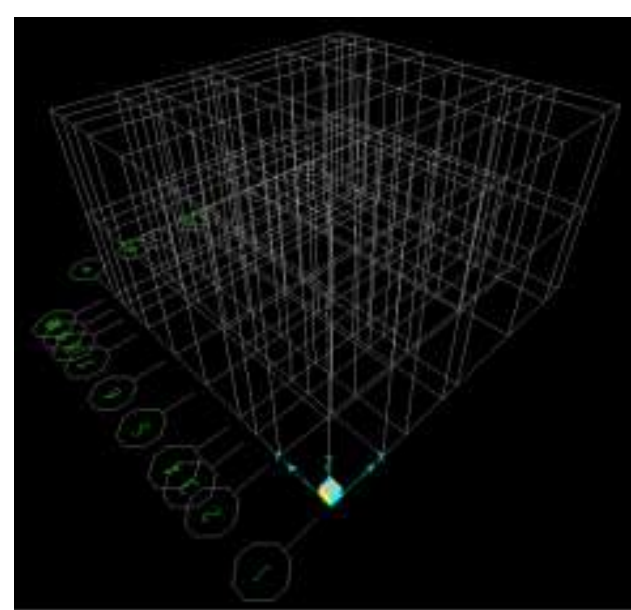

Gambar 11. Tampak 3D Grid setelah spasi diatur

f) Pastikan icon Snap to Points and Grid Intersections di toolbar samping kiri aktif.

2) Penentuan Jenis Material dan Penampang Pelat. Untuk menentukan jenis material yang dipakai pada pelat klik menu Define lalu klik Materials. Pada tab Materials pilih 4000Psi untuk material beton sedangkan untuk material baja tulangan pada tab Materials pilih A992Fy50, lalu klik Modify/Show Material untuk menyesuaikan material dengan data 
yang akan digunakan. Tampilan kotak Define Materials, Material Property Data dapat dilihat pada Gambar 12.

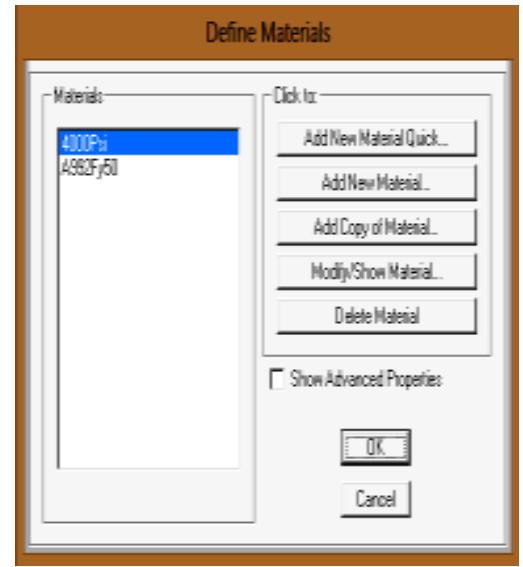

Gambar 12. Kotak Define Materials

Data material beton yang dipakai diisi pada kotak Material Property Data dengan rician sebagai berikut:

Material type $=$ Concrete (beton)

Berat jenis beton $=2,4 \times 10^{-5} \mathrm{~N} / \mathrm{mm}^{3}$

Modulus elastisitas beton $=$

$23452,9529 \frac{\mathrm{N}}{\mathrm{mm}}^{2}$

Poisson Ratio beton $\quad=0,2$

Koefisien muai $=9,9 \times 10^{-6}$

Mutu beton (f'c) $=24,9 \mathrm{MPa}$

Setelah data diatas diinput ke dalam kotak Material Property Data lalu klik $O K$. Gambar input data material beton pada kotak tampilan Material Property Data dapat dilihat pada Gambar 13.

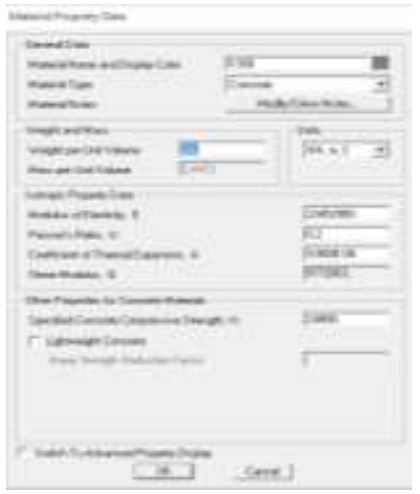

Gambar 13. Kotak Material Property Data untuk material beton
Setelah data diatas diinput ke dalam kotak Material Property Data lalu klik OK.Gambar input data material baja pada kotak tampilan kotak Material Property Data dapat dilihat pada Gambar 14.

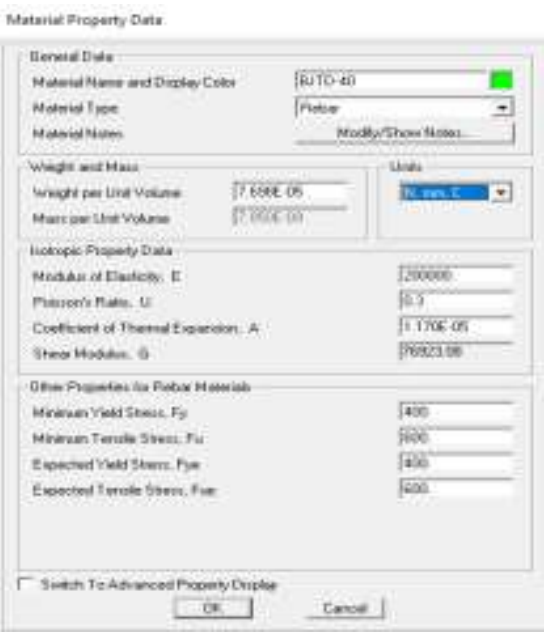

Gambar 14. Kotak Material Property Data untuk material baja tulangan

Untuk membuat penampang balok dan kolom digunakan menu Define Section Properties - Frame Sections. Selanjutnya akan ditampilkan kotak Frame Properties yang dapat dilihat pada Gambar 15.

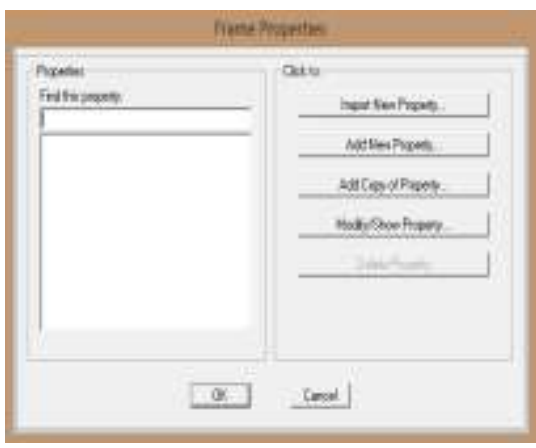

Gambar 14. Kotak Frame Properties

Untuk membuat penampang baru, klik Add New Properties pada kotak Frame Properties. Lalu pilih jenis material Concrete dan klik Rectangular sebagai jenis penampang untuk penampang yang 
digunakan berbentuk persegi. Tampilan kotak Add Frame Section Property dapat dilihat pada Gambar 15.

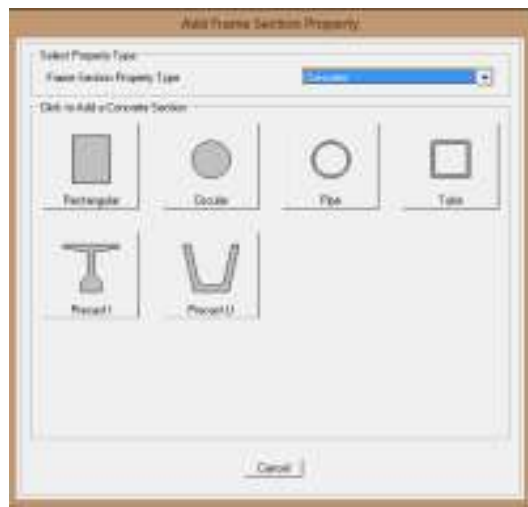

Gambar 15. Kotak Add Frame Section Property

Ketik nama balok pada kotak Section Name, lalu isi ukuran penampang pada tab Dimensions. Selanjutnya pilih jenis material yang digunakan. Tampilan input pada kotak Rectangular Section dapat dilihat pada Gambar 16 untuk section balok dan Gambar 17 untuk section kolom.

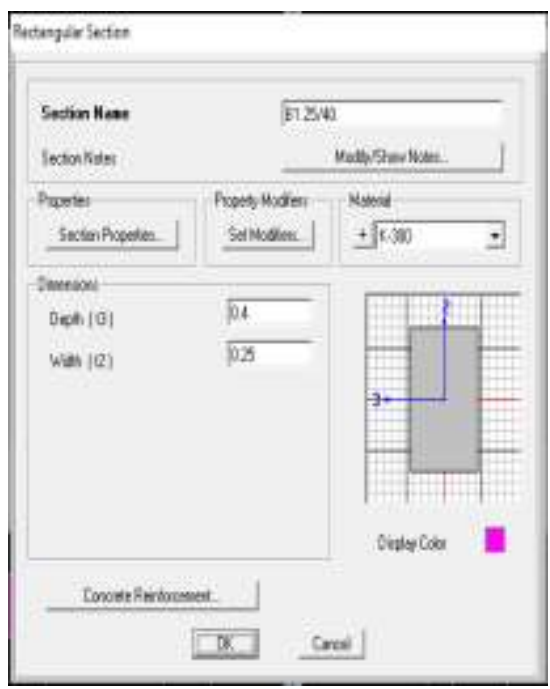

Gambar 16. Kotak Rectangular Section (Balok)

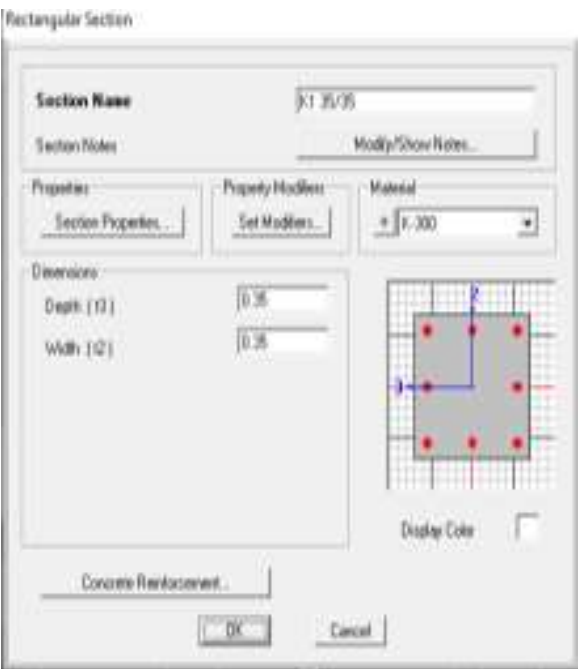

Gambar 17. Kotak Rectangular Section (Kolom)

Untuk menentukan penulangan pada penampang, klik Concrete Reinforcement. Pilih material tulangan ulir U-40 untuk Longitudinal Bars, sedangkan untuk tulangan sengkang pilih material tulangan polos U-24 pada tab Confinement Bars. Untuk membuat penampang kolom, gunakan tab Column sedangkan untuk membuat penampang balok, gunakan tab Beam. Selanjutnya isi data tulangan yang akan digunakan pada penampang. Lalu klik OK. Tampilan kotak Reinforcement Data dapat dilihat pada Gambar 18 dan 19.

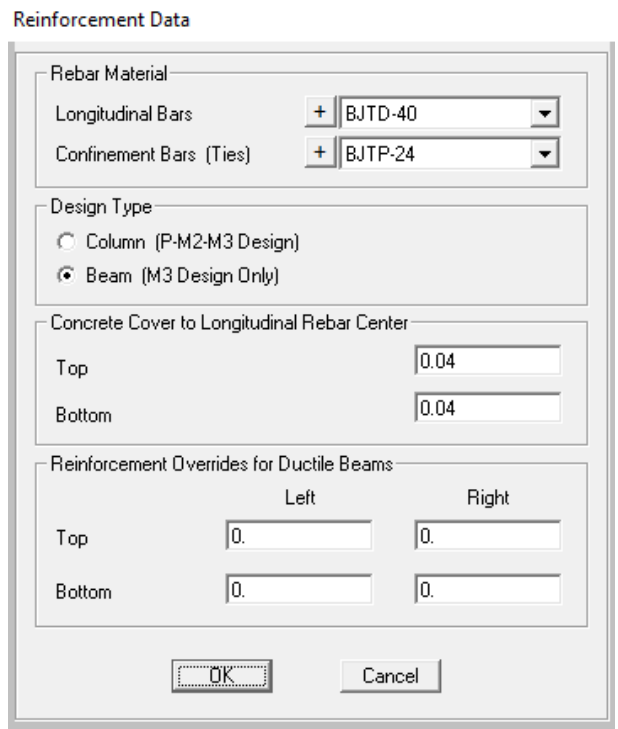

Gambar 18. Kotak Reinforcement Data (Balok) 


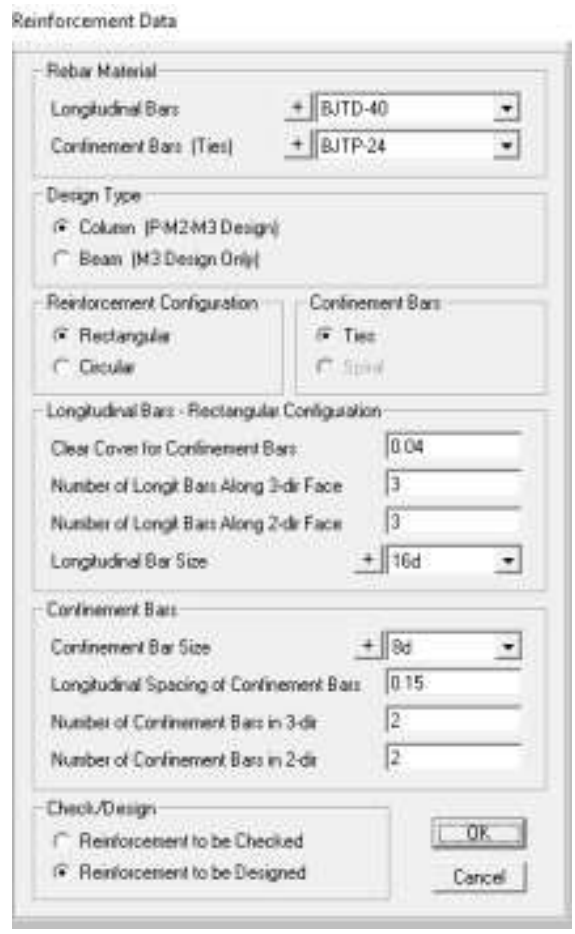

Gambar 19. Kotak Reinforcement Data (Kolom)

Pengaturan penampang pelat dapat dilakukan dengan cara klik menu Define lalu klik Section Properties selanjutnya klik Area Sections.

Pada kotak Area Sections klik dropdown lalu pilih Shell, lalu klik Add New Section pada tab Click to untuk membuat sebuah penampang baru. Tampilan kotak Area Section dapat dilihat pada Gambar 20.

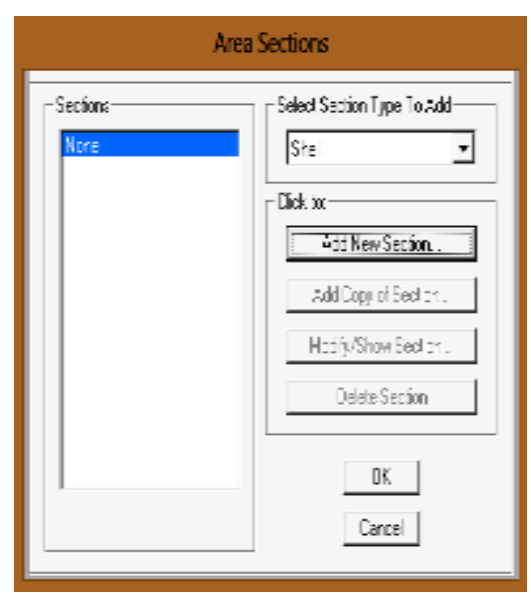

Gambar 20. Kotak Area Sections
Data penampang pelat yang akan didesign diisi pada kotak Shell Section Data dengan rician sebagai berikut:

Type = Shell-Thin (pelat tipis)

Material = Beton dengan mutu K300

Thickness $/$ ketebalan $=120 \mathrm{~mm}$

Untuk menambahkan data baja tulangan yang dipakai pada pelat klik Modify/Show Shell Design Parameters pada tab Concrete Shell Section Design Parameters. Lalu klik drop-down untuk memilih material U-24 sebagai Rebar Material dalam kotak Concrete Shell Section Design Parameter kemudian klik OK. Tampilan kotak Concrete Shell Section Design Parameter dapat dilihat pada Gambar 21.

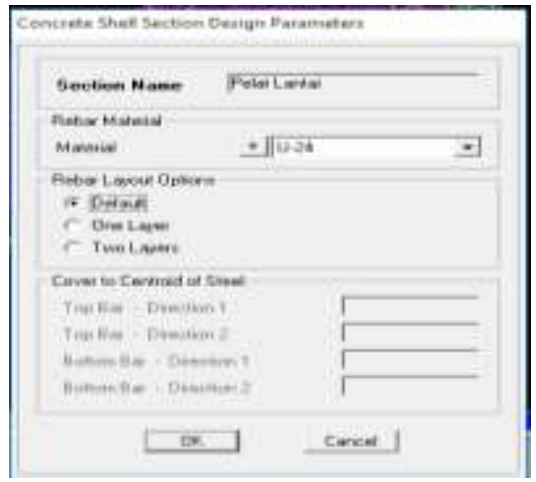

Gambar 21. Pengaturan material baja tulangan dalam kotak Concrete Shell Section Design Parameter

3) Penggambaran Model Struktur

Klik tombol Quick Draw Frame di toolbar sebelah kiri untuk menggambarkan balok dan kolom. Dan sesuaikan jenis penampang dengan yang tertera pada gambar kerja. Selanjutnya Klik tombol $\square$ Quick Draw Area Element di toolbar sebelah kiri untuk menggambar pelat lalu klik grid dimana pelat akan digambar. Atau dapat pula dilakukan dengan klik Draw - Quick Draw Area Element - lalu pilih Area Section yang telah dibuat sebelumnya. Selanjutnya pelat akan 
tergambar secara otomatis berdasarkan grid yang telah diatur sebelumnya, sehingga pelat sudah otomatis terbagi menjadi beberapa pias yang terbentuk mengikuti jarak spasi grid. Penggambaran pelat pada SAP2000 versi 14 dapat dilihat pada Gambar 22.

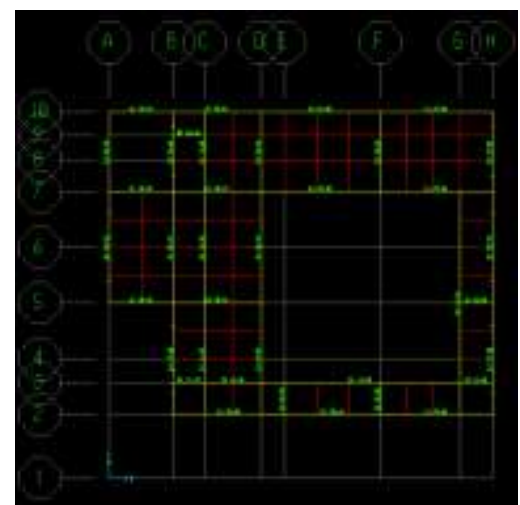

Gambar 22. Penggambaran Struktur pada SAP2000 versi 14

4) Memberikan Tumpuan pada Kolom

Klik icon Set Select Mode \& lalu blockujung kolom, selanjutnya klik menu Assign-Joint-Restraints. Kemudian klik tanda $\sqrt{\nabla}$ pada kotak Joint Restraints untuk menentukan jumlah Degree Of Freedom (DOF). Untuk tumpuan jepit tidak ada perpindahan dan rotasi pada semua arah. Untuk itu, maka semua perpindahan dan rotasi pada tab Restraints in Joint Local Directions di klik tanda ${ }^{\nabla}$. Untuk langkah yang lebih cepat dapat digunakan icon $\downarrow$ mada tab Fast Restraints. Tampilan kotak Joint Restraints dan tampak 3D struktur gedung setelah diberi tumpuan dapat dilihat pada Gambar 23 dan Gambar 24.

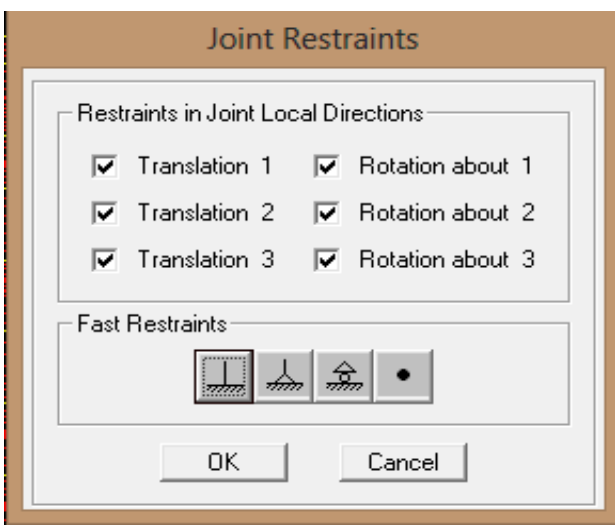

Gambar 23. Penggambaran Struktur pada SAP2000 versi 14

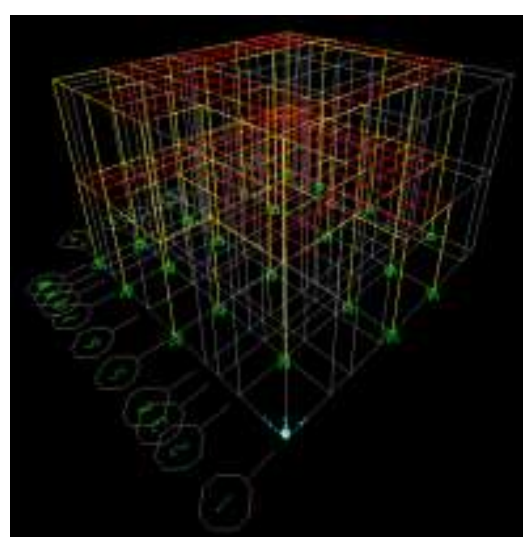

Gambar 24. Tampak 3D struktur gedung setelah diberikan tumpuan

5) Pembebanan Pada Struktur

Jenis - jenis beban yang dipakai dalam analisis dapat di-input pada SAP2000 versi 14 dengan cara klik menu Define - Load Pattern. Beban yang diperhitungkan beban mati (dead load), beban mati tambahan (super dead), beban hidup (live load). Jika berat sendiri pelat dihitung di luar perhitungan SAP2000 maka Self Weight Multiplier nilainya dibuat 0 , sedangkan jika berat sendiri pelat dihitung oleh SAP2000 maka nilai Self Weight Multiplier adalah 1.

Untuk menambah beban baru dapat dilakukan dengan cara memberikan nama beban pada tab Load Pattern Name menentukan jenis beban pada tab Type dalam kotak Define Load Patterns. Input 
beban pada kotak Define Load Patterns dapat dilihat pada Gambar 25.

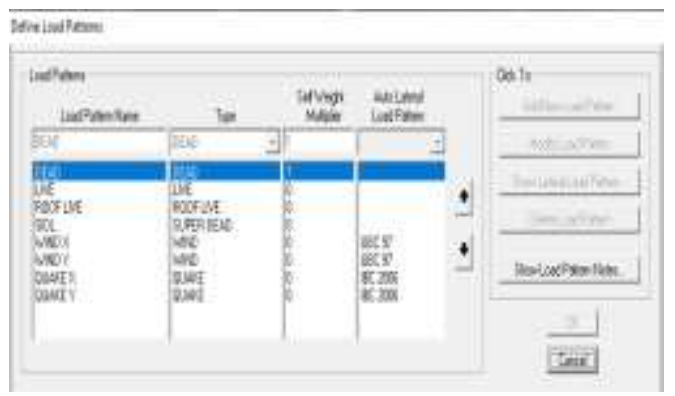

Gambar 25. Input beban yang diperhitungkan pada SAP2000 versi 14

Dalam analisis, beban mati tambahan diperhitungkan dan dikombinasi bersama dengan beban mati sehingga pada SAP2000 kedua jenis beban tersebut harus digabungkan. Untuk melakukan hal tersebut, klik menu Define - Load Cases. Pada kotak Define Load Cases klik DEAD pada tab Load Case Name lalu klik Modify/Show Load Case. Kemudian pada drop-down Load Applied pada kotak Load Case Data ditambahkan beban SIDL, klik OK. Penggabungan beban pada kotak Load Case Data dapat dilihat pada Gambar 26.

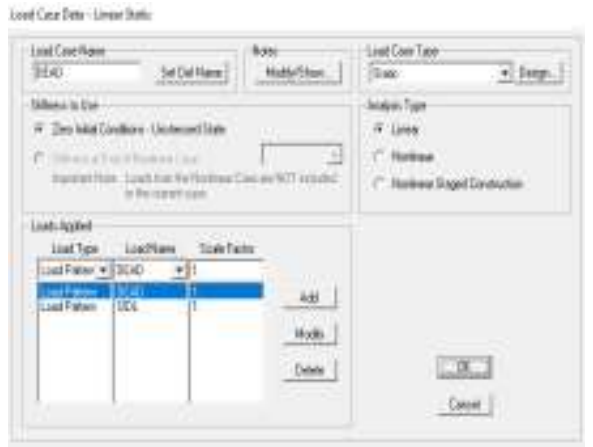

Gambar 26. Menggabungkan beban mati (dead load) dan beban mati tambahan (super dead)

Saat kembali pada kotak Define Load Cases, klik SIDL pada tab Load Case Name lalu klik Delete Load Case. Hal ini dilakukan untuk menghindari terjadinya beban ganda karena beban mati tambahan (super dead) sudah dimasukkan ke dalam komponen beban mati (dead load). Tampilan Item load case setelah penggabungan beban mati (dead load) dan beban mati tambahan (super dead) pada kotak Define Load Cases dapat dilihat pada Gambar 27.

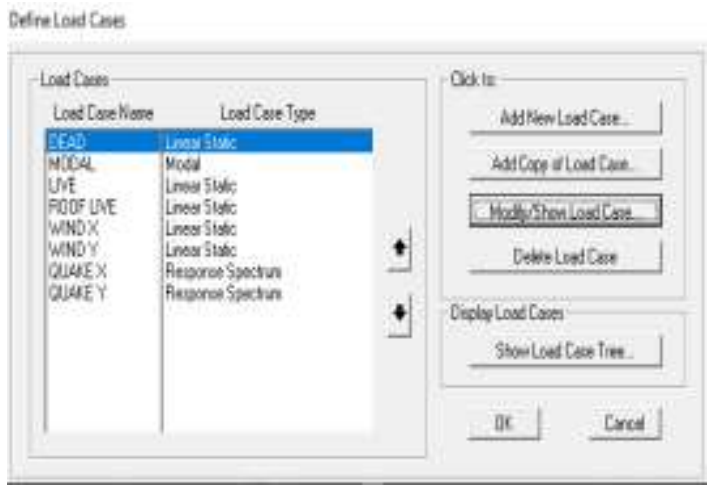

Gambar 27. Item load case setelah penggabungan beban mati (dead load) dan beban mati tambahan (super dead)

Klik menu Define - Load Combinations untuk memasukkan kombinasi pembebanan. Lalu klik Add New Combo untuk menambah kombinasi baru. Masukkan nilai faktor kombinasi pada tab Scale Factor. Selanjutnya klik Add lalu klik OK. Klik icon Set Select Mode lalu block semua bagian pelat. Klik menu Assign - Area Loads - Uniform (Shell) untuk memberikan beban pada seluruh bagian struktur. Masukkan besarnya beban yang bekerja pada pelat lalu klik Add to Existing Loads kemudian klik $O K$.

6) Meshing/ Pembagian Pias Pada Pelat

Meshing / pembagian pias pada pelat dalam SAP2000 berfungsi untuk mengakomodasi transfer berat sendiri pelat. Selain itu meshing/ pembagian pias pada pelat juga berfungsi agar dapat memperoleh hasil analisis yang lebih detail dan lebih akurat. 
Untuk membagi pelat menjadi beberapa pias dapat dilakukan dengan cara Klik icon Set Select Mode 8 lalu block bagian pelat yang akan di-mesh. Klik menu Edit-Edit Areas - Divide Area. Lalu akan muncul kotak dialog seperti pada gambar 28.

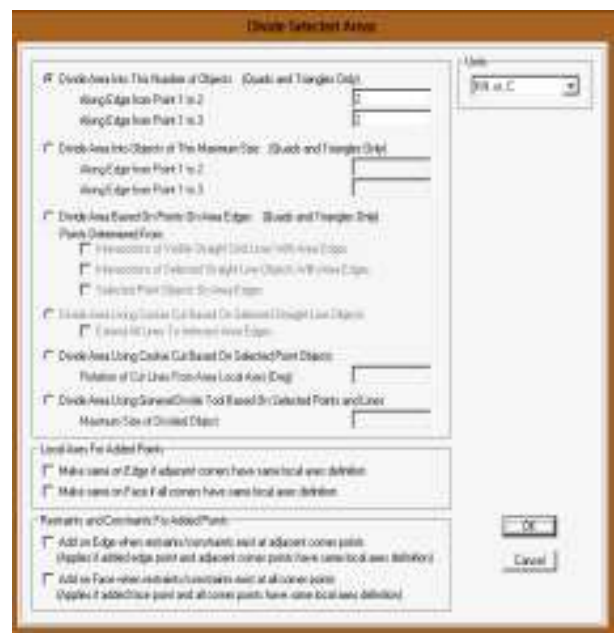

Gambar 28. Kotak Divide Selected Areas

Untuk membagi pelat menjadi jaringan 2 × 2 maka pada menu divide area into this number of objects ketik angka 2 pada along edge from point 1 to 2 (untuk sumbu x) serta ketik angka 2 pada along edge from point 1 to 3 (untuk sumbu y). Setelah pelat terbagi menjadi pias $2 \times 2$, perlu digunakan generate edge costraint untuk membuat pelat yang pembagiannya tidak rata dapat bekerja bersama sebagai satu kesatuan utuh.

Klik icon Set Select Mode 8 lalu block semua bagian pelat. Klik menu Assign-Area - Generate Edge Costraints - Create Costraints around Object Edges - Klik OK. Tampilan kotak Assign Edge Constraintsdapat dilihat pada Gambar 29.

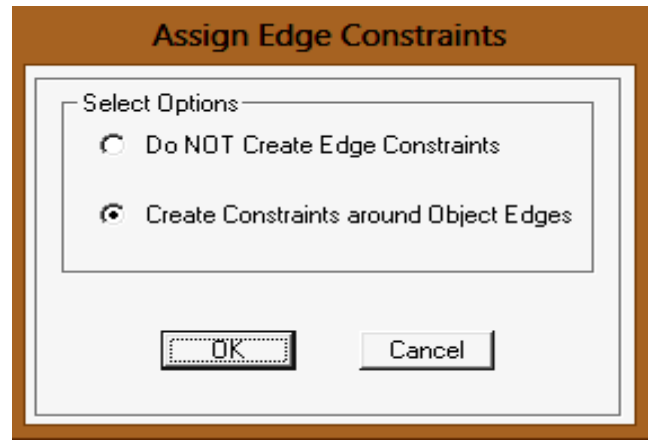

Gambar 29. Kotak Assign Edge Costraints

7) Analisis Struktur Menggunakan SAP2000

Setelah data-data struktur selesai diinput maka sudah dapat dilakukan analisis. Klik menu Analyze - Set Analysis Options Lalu akan muncul kotak Analysis Options. Klik Space Frame pada Plane Grid pada Fast DOFs atau dapat memilih DOF's secara manual pada Available DOFs untuk memilih elemen 3D. Kotak pemilihan jenis analisis yang digunakan pada SAP2000 dapat dilihat pada Gambar 30.

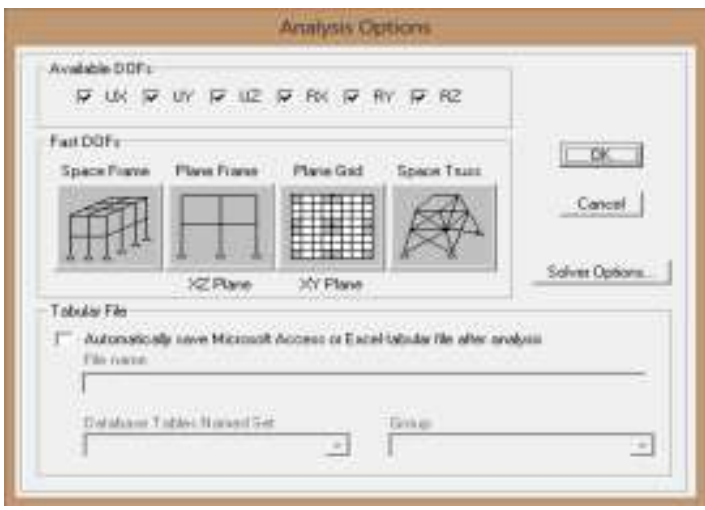

Gambar 30. Pemilihan jenis analisis yang digunakan pada SAP2000

Klik menu Analyze - Run Analysis Run Now. Setelah itu akan muncul hasil analisis pelat datar yang diperlukan. Dari hasil analisis didapat diagram momen, diagram lintang, diagram axial pada balok dan kolom serta momen pada plat dapat dilihat pada Gambar 31 sampai Gambar 34. 


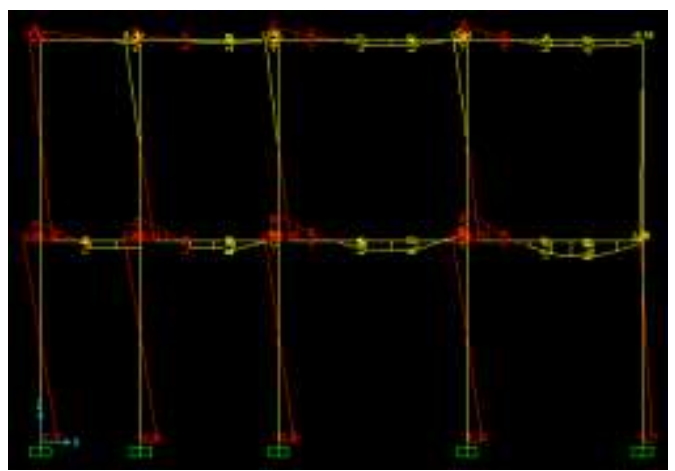

Gambar 31. Diagram Momen pada Balok dan Kolom

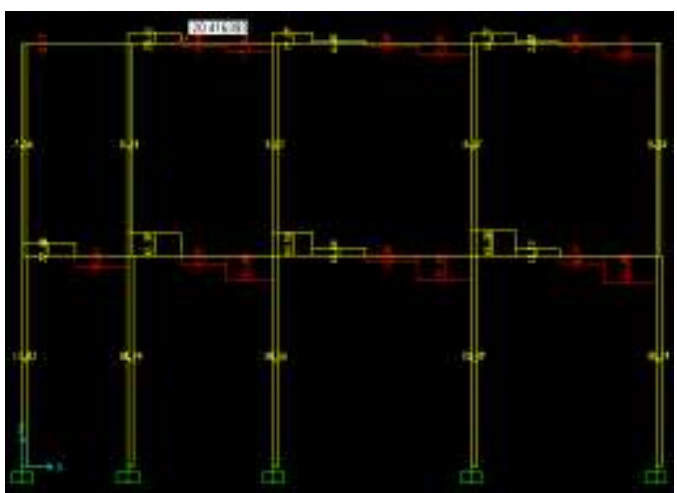

Gambar 32. Diagram Lintang pada Balok dan Kolom

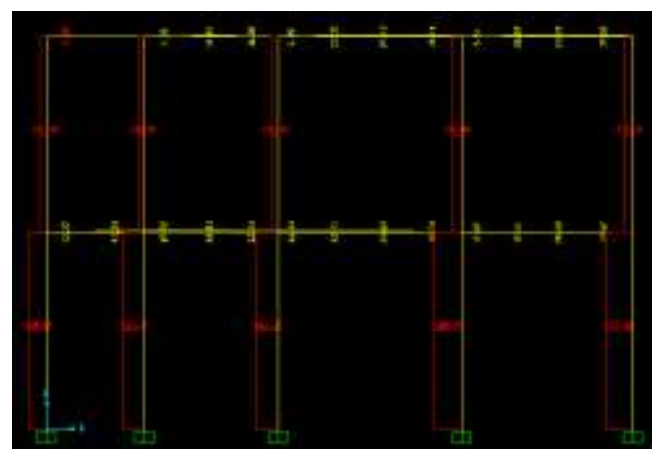

Gambar 33. Diagram Axial pada Balok dan Kolom

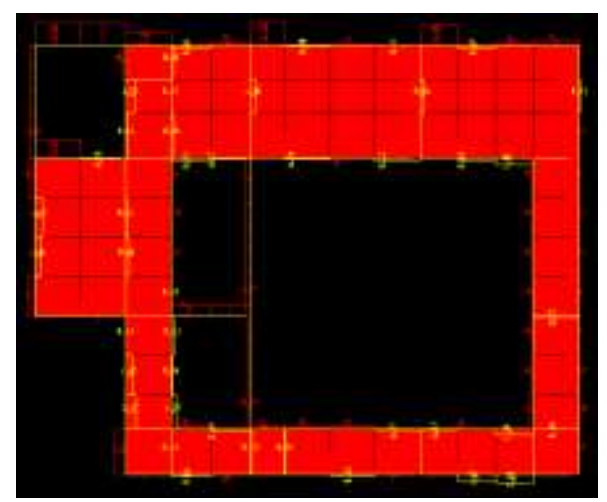

Gambar 34. Diagram Normal pada Balok dan Kolom

8) Perhitungan Luas Tulangan Perlu

Klik icon $\square \cdot$ untuk mendapatkan luas tulangan perlu pada masing-masing penampang balok dengan pelat. Luas tulangan perlu pada balok di lantai 2 dapat dilihat pada Gambar 35.

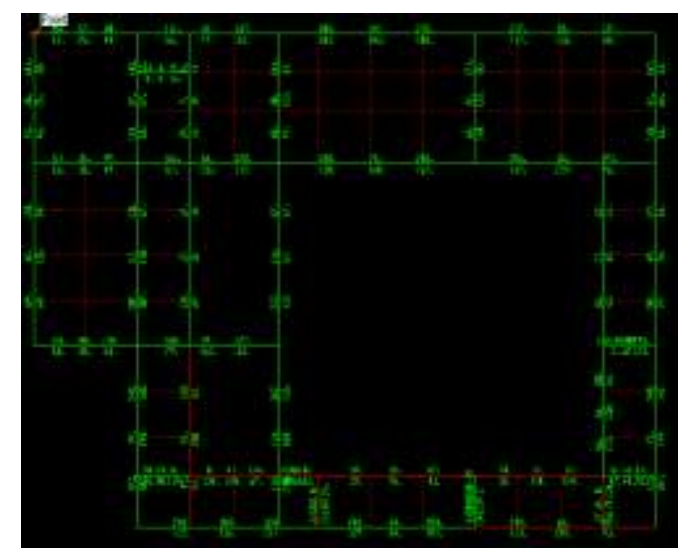

Gambar 35. Luas tulangan perlu pada balok dan kolom

\section{Perhitungan Kapasitas Penulangan}

\section{a. Pelat}

Penentuan momen dari masing-masing plat dapat mengikuti ketentuan dalam buku table Timoshinko. 


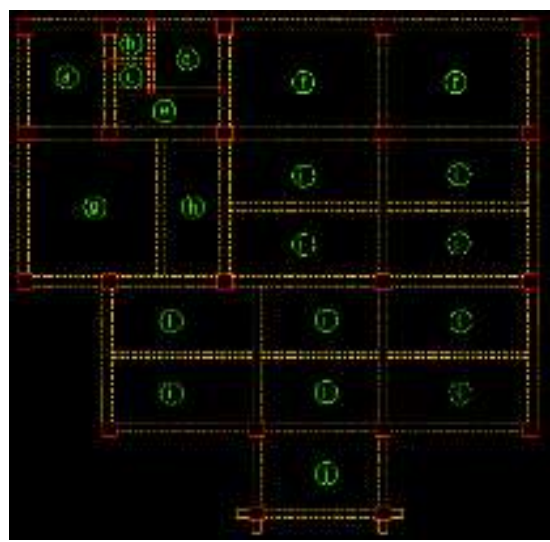

Gambar 36. Pembagian Panel pada Pelat Lantai

Berdasarkan perhitungan hasil analisis SAP2000 didapat momen maksimum pada plat sebagai berikut :

Tabel 4. Data-data plat lantai

\begin{tabular}{|c|c|}
$\mathbf{f} \mathbf{c}$ & $24.9 \mathrm{Mpa}$ \\
\hline $\mathbf{f y}$ & $240 \mathrm{Mpa}$ \\
\hline $\mathbf{h}$ & $120 \mathrm{~mm}$ \\
\hline $\mathbf{p}$ & $20 \mathrm{~mm}$ \\
\hline$\phi$ Tul & $10 \mathrm{~mm}$ \\
\hline $\mathbf{d x}$ & $95 \mathrm{~mm}$ \\
\hline $\mathbf{d y}$ & $85 \mathrm{~mm}$
\end{tabular}

Tabel 5. Nilai Mlx, Mly, Mtx, dan Mty

\begin{tabular}{|c|c} 
Mlx & $2.900 \mathrm{kNm}$ \\
Mly & $4,0100 \mathrm{kNm}$ \\
Mtx & $-2.1516 \mathrm{kNm}$ \\
Mty & $-2.8200 \mathrm{kNm}$
\end{tabular}

\section{KESIMPULAN DAN SARAN}

Berdasarkan uraian perhitungan analisis yang telah dilakukan dapat disimpulkan bahwa Evaluasi kekuatan struktur kolom pada Pembangunan Gedung Kantor Kelurahan Kampung Baru Raya yang terpasang pada kolom K1 35 x 35 dengan jumlah tulangan pokok 4 - D15 dan sengkang $\phi 8-100$ sedangkan lebih kecil daripada tulangan hasil analisis yakni 8-D16 dan sengkang $\phi 8-50$. Tulangan yang terpasang di lapangan kurang dari persyaratan pmin kolom yaitu 1\% (seharusnya dipasang minimal 7-D16) sehingga perlu dilakukan perkuatan struktur agar kolom tersebut dapat bertahan sesuai umur rencana. Untuk kekuatan struktur balok pada Pembangunan Gedung Kantor Kelurahan Kampung Baru Raya yang terpasang di lapangan yaitu tumpuan atas sebesar 4-D16, tumpuan bawah 3-D16, lapangan atas 3-D16, lapangan bawah 4-D16, dam jumlah tulangan yang didapat dari hasil analisis yaitu tumpuan atas Balok B1 hasil analisis sebesar 3-D13, tumpuan bawah 2-D13, lapangan atas 2-D13, lapangan bawah 2-D13. Perbedaan tersebut terjadi karena adanya perbedaan asumsi pembebanan pada proses perencanaan, namun jumlah tulangan yang terpasang di lapangan terpasang lebih banyak dibandingkan hasil analisis maka balok yang terpasang sudah aman berdasarkan perencanaan menggunakan peraturan pembebanan yang terbaru.

Untuk kekuatan struktur pelat pada Pembangunan Gedung Kantor Kelurahan Kampung Baru Raya yang terpasang di lapangan yaitu $\phi 10-200$ dan hasil analisis didapat $\phi 10-125$ untuk arah $\mathrm{x}$ dan $\phi 10-150$ untuk arah y. Perbedaan tersebut terjadi karena adanya perbedaan asumsi pembebanan pada proses perencanaan. Karena hasil analisis dibutuhkan lebih banyak tulangan dibandingkan kolom eksisting, sehingga perlu dilakukan evaluasi dan perkuatan struktur jika diperlukan agar kolom tersebut dapat bertahan sesuai umur rencana. Kapasitas elemen struktur eksisting yang terpasang tidak aman jika dilakukan pembangunan kembali tanpa dilakukan perkuatan struktur.

\section{DAFTAR PUSTAKA}

Hariono. 2002. "Beton Bertulang"

Istimawan Dipohusodo. 1994. "Struktur Beton Bertulang Jenis Kolom Beton". Nawy,1998 "Kolom”

PBI 1971 N.I.-2 ke SNI 03-2847-2002 Satuan dan Benda Uji Beton

PBI. 1971. "Tabel untuk penentuan momen plat" 
PBI. 1983. "Berat sendiri bahan bangunan dan komponen gedung. Beban hidup pada lantai gedung"

PPIUG. 1983. "Beban Gempa"

PPPURG. 1987. "Pedoman Perencanaan Pembebanan untuk Rumah dan Gedung"

SK SNI T-15-1991-03., "Kolom, Balok, Plat Lantai"

SNI 03-2847-2002. "Daerah tumpuan dan lapangan Pelat dua arah".

SNI 1726-2012. "Baja Tulangan Beton"

SNI 03-2846-2002. "Sifat Fisik Baja Tulangan" 